\title{
O DINHEIRO E SUAS DIVERSAS FACES NAS ELEIÇÕES MUNICIPAIS EM PERNAMBUCO
}

Jorge Mattar Villela

\section{A reciprocidade e as eleições}

Dentre todos os temas estudados na história da antropologia, talvez não haja um cuja ubiqüidade seja comparável à da reciprocidade. Mesmo antes do influente artigo de Marcel Mauss (1924), ele já estava presente em diversos textos, livros e pesquisas. Aparece nos estudos que enfocam os mais variados subtemas, tais como parentesco, economia, política e religião. Sua onipresença é tal que gerou, nas últimas décadas, uma intensa discussão acerca de sua real validade e de sua força explicativa. A influência de Mauss extrapolou os domínios da sociologia e da antropologia e atingiu a história, entre outros motivos, pela versatilidade dos estudiosos e pelo grande alcance das obras dos filiados ao Année Sociologique, dos alunos e alunas de Mauss e dos discípulos desses alunos.

Nos últimos tempos, a retomada das etnografias concentradas na $\mathrm{Me}$ lanésia atualizou o debate acerca da reciprocidade, não só localmente, mas também renovando as teorias antropológicas vigentes (p.ex., Strathern 1988; Weiner 1985 e 1992; Gregory 1982). Um destes estudos (Gregory 1982) sustenta que as análises antropológicas sobre a reciprocidade serviram-se dos textos setecentistas e oitocentistas de economia política, tendo desprezado a outra vertente, a economia neoclássica. Para ele, apenas a primeira poderia dar conta dos fatos postos em relevo pelas observações etnográficas que ganharam força a partir do fim do século XIX. Ao referirse às relações estabelecidas nas economias baseadas em clãs por oposição àquelas baseadas em classes, que geram, respectivamente, sistemas econômicos de dons e de mercadorias, sempre seguindo os princípios da economia política e sobretudo os postulados de Marx, Gregory arrola as características das economias do dom: produção de vínculos de dependência entre as partes que transacionam bens, a faceta personalizada das coisas 
em circulação e, como já ressaltava Mauss (1995 [1925]), a circulação de pessoas antes que de coisas.

Desde Durkheim (1960 [1893]) e Mauss (1994 [1921]; 1994 [1924]; 1993 [1925]) — embora haja quem, como Beaucage (1995) e Gouldner (1960), remonte a Hobbes e Locke - até trabalhos relativamente recentes, a reciprocidade tem sido considerada cimento, fundamento e até a fundadora das relações sociais, e a condição de possibilidade da passagem da natureza à cultura (Lévi-Strauss 1971 [1966]; cf. Simonis 1979 [1968]), conforme lembra Weiner (1992:25). Além disso, não pode ser esquecida a persistente constatação de sua universalidade por autores tão díspares e distantes no tempo quanto Westermarck e Gouldner.

O contratualismo subjacente às teorias da reciprocidade - particularmente explicitado no célebre artigo de Sahlins (1976 [1968]) — permite entrever o modo como a filosofia política, de Hobbes a Rousseau, as inspirou (de Mauss a Lévi-Strauss). Deve ser analogamente ressaltada a influência de um certo hegelianismo resultante dos cursos de Alexander Kojève, cujos frutos apareceram, conforme notou Karsenti (1994), nas obras de inúmeros intelectuais franceses, estivessem eles nas aulas do mestre ou não. Conforme sugeri em outro lugar (Villela 2001), o espectro das noções de reconhecimento e dialética surge um pouco por todo lado, em autores como Bataille (1975), Lefort (1979 [1951]) e Bourdieu (1988 [1965]; 1994 [1980]; 1996), sendo que, neste último, o reconhecimento assume a forma da acumulação de um "capital simbólico".

Um outro elemento componente do cânon das teorias da reciprocidade, em que pese sua heterogeneidade e a ausência de uma definição precisa para o conceito $^{1}$, é a noção de equivalência e o modo como ela contribui para a homeostase e o equilíbrio social, embora tais hipóteses venham sendo refutadas desde a década de 1990 pelo menos (p.ex., Weiner 1992). De Mauss (1993 [1925]) a Sahlins (1965; 1968), passando pelas reflexões de Lévi-Strauss $(1942 ;$ 1967) e por um imenso rol de etnografias, o dom e a troca foram recorrentemente entendidos como um meio de impedir o conflito, e este considerado um fracasso daquele esforço. Clastres (1962; 1974 ; 1977), que constitui uma exceção a esta tendência quase generalizada na antropologia, inverteu a fórmula consagrada por Lévi-Strauss.

Os estudos dos sistemas políticos sofreram influências semelhantes. Antropólogos e sociólogos especializados nos estudos do clientelismo, cujas teorias expuseram a existência de contratos sociais em que, no mais das vezes, a parte dominada entrega sua liberdade e junto com ela sua lealdade e fidelidade esperando receber proteção, trabalharam com os mesmos pressupostos. Em muitas dessas pesquisas estão presentes as noções de reco- 
nhecimento, gratidão, equilíbrio e encetamento de relações sociais por meio da reciprocidade. Uma parte importante da literatura sobre patronagem e clientelismo no Brasil lidou com o processo eleitoral e com o modo pelo qual, tradicionalmente, os políticos obtêm votos para as suas candidaturas entregando, em troca, recursos tangíveis e intangíveis aos eleitores ${ }^{2}$.

Como mostram etnografias recentes, uma abordagem atual das eleições deve levar em consideração a função cada vez mais relevante do dinheiro, tanto sob forma direta quanto transformado em recursos diversos, como meio de angariar votos e conquistar eleitores. O tema foi tratado sob enfoque etnográfico, no âmbito da antropologia brasileira, ao menos por dois autores (Palmeira 1992; Goldman 2000). Segundo Palmeira, a chamada compra de votos ocorre sempre que o dinheiro é usado abusivamente ou sob sua forma pura e imediata. Para Goldman, existe certa ambivalência dos sentidos atribuídos a essa prática.

A aproximação do processo eleitoral à circulação de dons é encontrada em várias épocas e latitudes. Segundo diversos estudos, os intervenientes encaravam com dificuldade a ausência de dons durante este período. Candidatos e eleitores parecem considerá-la uma época de dissipação de riquezas e serviços cujas reservas tornam-se ilimitadas. De acordo com os dados de minha pesquisa, ambas as partes, cujas posições muitas vezes confundem-se e trocam-se (o que não desfaz a tensão entre elas), põem-se de acordo com a seguinte opinião: a época da política é o tempo em que alguns querem votos e outros querem favores. Aos que desejam os votos resta apenas dobrarem-se aos desejos dos que os detêm. E como corolário: os que obtiveram favores devem reconhecer-se devedores dos que os concederam, obrigando-se a retribuí-los levando a efeito a palavra empenhada na época do recebimento. Ao detentor dos favores resta honrar seus compromissos junto aos donos dos votos. Essa é a regra, declarada ou tácita. Resta saber o modo como ela responde ao funcionamento da máquina social e as formas como as regras podem ser legitimamente rompidas.

Este artigo pretende mostrar os modos como o dinheiro, se apresentado sob sua forma pura, monetária, torna instantânea e finita uma relação (eleitor/candidato) cujo alongamento da duração sob a forma credor/devedor é por vezes a mais desejável. Este alongamento, veremos, pode ser construído sobre bases semelhantes àquelas em que se encerra no momento da troca (recursos por votos). A duração e permanência da relação é obtida antes em virtude das táticas e estratégias de ambos, eleitores e candidatos, do que da natureza e tipo dos dons postos em circulação. Mas é visível também o modo como o dinheiro pode adquirir a aparência de um dom que faça perdurar a relação credor/devedor em proveito de ambas as partes. 


\section{Trabalho de campo e obtenção do material da pesquisa}

Os dados do texto que se segue foram obtidos por meio de trabalho de campo em três municípios situados na mesorregião do Sertão de Pernambuco, realizado em três períodos (um de seis meses e dois de 45 dias, sendo o segundo durante as eleições municipais de 2000), perfazendo um total de nove meses. Os municípios em questão têm, respectivamente, populações de cerca de 16 mil, 70 mil e 20 mil habitantes e colégios eleitorais de 12 mil, 45 mil e 12 mil eleitores ${ }^{3}$.

O primeiro período de trabalho de campo ocorreu entre os meses de agosto e fevereiro de 1999, mais de um ano, portanto, antes das eleições municipais - que ocorreriam em outubro de 2000. Desde os primeiros dias, tornou-se inevitável constatar a relevância do tema da política ${ }^{4}$ para uma parte substancial da população, dada a freqüência e a intensidade com que este assunto era tratado. É possível, então, afirmar que fui tragado por essa preocupação dos intervenientes do processo, antes que tivesse a intenção previamente refletida de investigá-lo.

O período no qual dediquei-me exclusivamente ao estudo das eleições foi o segundo da permanência em campo, entre setembro e outubro de 2000. Em virtude do calor da hora, os dados chegaram-me às mãos sem esforço, as eleições transformadas em assunto palpitante, monopolizando as conversas em cada esquina, todos os atos, e colorindo as ruas com as cores das facções em confronto. O tema eleitoral ocupava todos os espaços e todos os tempos da vida social 5 .

Tentei inicialmente, como método de trabalho, ligar-me a um candidato a vereador por um dos municípios. Tentativa fracassada pelo número de ações evasivas e de encontros frustrados. Mudando de estratégia, fiz algumas viagens de pedidos de votos com outros candidatos ou pessoas a serviço de candidatos e, sobretudo, conversei com alguns dos meus antigos colaboradores de pesquisa, todos de algum modo envolvidos na campanha. Obtive também total colaboração dos juízes das três comarcas e tive à disposição todos os dados referentes às seções eleitorais que pesquisei, além de ter acesso a algumas delas durante o pleito.

\section{O voto e o dinheiro nas eleições: reciprocidade, redistribuição e mercado ${ }^{6}$}

No contexto geral das teorias da reciprocidade, ao doador costuma-se atribuir uma posição superior em relação ao receptor, embora sempre reversível de acordo com o sentido das dádivas. Negligenciou-se o fato, conforme 
lembrou Veyne (1976), que as ofertas ocorrem de maneiras diferentes, com diversos objetivos, recebendo esse ato vários significados, segundo, por exemplo, a posição ocupada previamente por quem dá e por quem recebe.

Na circulação de dons estão envolvidas as formas e o valor, equivalentes ou não, do que é trocado, notadamente segundo as teorias que deram excessiva importância à própria equivalência (cf. Gouldner 1960:171$172)^{7}$. No caso aqui enfocado, como em todos os estudos concernentes a eleições, defrontamo-nos com uma espécie de reciprocidade que não é nem "heteromórfica" nem "homeomórfica" (Gouldner 1960:172) . As coisas dadas pelos candidatos não se assemelham nem em valor nem em forma às que recebem em retribuição, se retribuição houver. O que um eleitor recebe em troca de seus votos, quando e se recebe, a custo poderia ser comparado com eles. Ademais, a celebrada "obrigação de retribuir" é equívoca e falha ${ }^{8}$. Portanto, nem equivalências, nem valor prévio relativo à ação de dar ou de receber, nem obrigação de retribuir presidem a circulação de recursos no processo eleitoral por mim observado.

Além disso, a circulação e a produção de recursos derivadas das eleições misturam noções tradicionalmente distinguidas pelos cientistas sociais, como as de reciprocidade, redistribuição e mercado. Há uma hesitação constante entre os três, dada a ambigüidade da posição hierárquica de eleitores e candidatos, uns em relação aos outros e enquanto políticos e eleitores. Do mesmo modo, dons e mercadorias transmutam-se uns nos outros incessantemente, impedindo uma classificação nítida ${ }^{9}$. Quanto aos agentes das transações, ora são patrões e clientes, ora parceiros comerciais, ora parentes, ora compadres e, em certos momentos, apenas compradores e vendedores.

Há uma outra ambigüidade, talvez derivada das demais: a da valoração atribuída, do ponto de vista nativo, ao uso do dinheiro. Um dos valores atribuídos a ele (o negativo) aparece quando, ao abordar determinados eleitores, candidatos ou seus prepostos renunciam ao uso do dinheiro, oferecendo àqueles benefícios que não monetários. Por outro lado, o valor positivo do dinheiro é explicitado quando se trata de outra classe de eleitores para quem, segundo a avaliação de um informante, não existe política nem campanha eleitoral sem o emprego do dinheiro ou de outros bens materiais que a ele se assemelhem, ou seja, bens monetarizados, ou interpretados como tais. De modo que o valor atribuído ao dinheiro compõe-se com o atribuído às pessoas. O dinheiro serve muito mais para saldar o preço das pessoas do que o das coisas, conforme observou Godbout (1999) a respeito da "moeda primitiva", na esteira das teorias de Mauss (1993 [1925]). No entanto, é preciso ter em mente que 
as transações eleitorais são efetuadas com a moeda moderna, habilitada a cumprir as funções de mensurar o valor dos bens, permitir sua circulação, quitar dívidas materiais e de ser um equivalente geral de valor, ao contrário do que ocorria com as "moedas primitivas".

É a avaliação heterogênea e hierarquizada das pessoas e dos grupos um dos fatores responsáveis pela variação dos dons e das promessas de candidatos segundo os eleitores e sua condição social. O que não implica dizer que necessariamente aos pobres oferece-se dinheiro e aos ricos, favores. Tanto se pode oferecer dinheiro quanto favores, independentemente da condição socioeconômica. Ou ainda, o dinheiro pode estar embutido no próprio favor e vice-versa. Se há mercantilização das relações eleitorais de votos, não se trata de mercantilização despersonalizada.

É bem verdade que no caso em estudo poucos são, proporcionalmente, os eleitores considerados muito caros pelos candidatos. O que não implica que todos se vendam ao primeiro que apareça com uma dentadura ou uma promessa de eletrificação. Os votos, freqüentemente, obtêm-se mais como o fruto da sedução ou das "lealdades fundamentais" (Palmeira 1992:27) sustentadas às custas do elemento material, ao qual se soma o elemento da esperança que é vinculado às promessas e à história pessoal e familiar de quem promete.

Uma forma de uso de dinheiro nas classes altas são os investimentos de comerciantes e fazendeiros nas campanhas de candidatos ao Legislativo e ao Executivo. Por meio deste expediente, produz-se um crédito a ser pago ao longo do mandato sob a forma de encomendas de serviços, de materiais e, sobretudo, de prestígio ${ }^{10}$, ou seja, de acesso a outros serviços e favores cujo alvo privilegiado são dependentes seus, atuais ou pretendidos. Um outro modo de produzir crédito junto a candidatos no qual o dinheiro assume diversas formas, entre elas a do salário, são os dons de trabalho. Neste caso, as expectativas são as mesmas. Trabalha-se por um candidato com os mesmos fins dos comerciantes e fazendeiros, mas também apostando em futuras carreiras políticas (embora muitas vezes elas surjam sem que tenha havido uma estratégia específica).

No espaço exterior às relações previamente existentes, os pedidos feitos por eleitores nas proximidades das eleições são encarados com desconfiança de parte a parte, com alto grau de reprovação moral, o que, contudo, não os torna raros. A mercantilização radical das eleições reduz a circulação recurso-voto/recurso-favor, do ponto de vista dos intervenientes, a uma relação exclusivamente (e explicitamente) troquista. Vender o voto no dia da eleição a um candidato qualquer supõe esgotar aí os créditos de que se poderia gozar, no futuro, com a transformação do voto em crédito, tornan- 
do duradouro o seu prestígio de eleitor. Ou, em outras palavras, fazendo de algo alienável (uma mercadoria) algo inalienável (um dom); produzindo, de uma troca cujo benefício é recebido imediatamente, um crédito pagável em diferido.

A existência de um mercado eleitoral expressa-se sob diferentes formas. Entre elas, nas relações de candidatos com seus "eleitores de voto múltiplo", na expressão de Palmeira (1992; 1996). Instrumentos do cens caché (Gaxie 1978), estes eleitores costumam pôr em circulação, além de seus votos e dos votos que conseguem obter, o seu trabalho. Mas não o fazem apenas a troco de bens tangíveis, embora não raramente recebam salários temporários. Fazem-no freqüentemente visando o aumento de seu prestígio junto aos empregadores e às comunidades às quais têm acesso; veiculam a circulação de recursos-favor contra os recursos-voto de que dispõem. Visam, ao mesmo tempo, manter e aumentar o conjunto de eleitores que fazem deles uma ponte entre suas necessidades e os recursos que anseiam. Assim, esse tipo de eleitor é capaz de ampliar — na medida de suas capacidades individuais, da sua história familiar, da firmeza dos laços que consiga tecer com os segmentos superiores da política - o número de votos de que dispõe, o "tempo da política" em que vive e, daí, mudar seu relacionamento com a política eleitoral. Deixar de ser um eleitor e tornar-se um candidato. Por meio desses expedientes, mercadoria transmuta-se em dom, reciprocidade em redistribuição e em mercado, e assim os blocos de dívida e crédito migram de parte a parte sem que se possa apontar, senão post factum, o beneficiário final e a fonte original.

Nessa perspectiva, compreende-se o que esteve em jogo no caso a seguir, de um "eleitor de voto múltiplo". Derrotado nas eleições legislativas municipais de 2000, um candidato cometeu um crime em sua cidade. Parente que era do assessor de um deputado federal que tentava fundar um núcleo eleitoral naquele município, pediu ao deputado uma soma em dinheiro que lhe permitisse abrir um negócio em Recife. Diante da informação do assessor que apresentava a ele o pleito de seu parente, o deputado perguntou àquele o que achava. Depois de hesitar, o assessor dissera-lhe que "não valia a pena", pois os votos de que o candidato dispunha não estariam a seu alcance, já que se tinha tornado um foragido da justiça. O dinheiro foi, então, negado. Sob a transação financeira mais evidente (votos do candidato a vereador contra investimento financeiro do deputado) esconde-se uma possível, porém não dada, transação de mais longa duração e mais aprofundados vínculos: a de um candidato de um nível superior da política com o seu "eleitor de voto múltiplo" de quem se teria tornado credor. Assim, a pretensão do foragido não era apenas fugir, nem muito menos 
simplesmente abrir um negócio. Era associar à fuga a proteção de um deputado, negociando com ele os votos de que se supunha ou de que se queria mostrar detentor. É um caso, não raro, de eleitor fazendo promessas a político. Neste caso, o foragido não pretendia simplesmente alienar seus votos em troca de dinheiro. Queria vínculos, por um lado. Por outro, não propriamente pela natureza do que era transacionado, mas pela situação em que se encontrava, estaria condenado à posição de submissão em relação ao deputado a quem dirigia um pedido. Isso para o caso de se confirmarem as promessas de votos. Se não se confirmassem, estariam canceladas todas a esperanças de crédito, e sua reputação na "pequena política" da "comunidade" (Bailey 1971) dos políticos profissionais estaria condenada.

\section{Troca e relação instantânea}

Se para os candidatos a alienação dos votos pode ser considerada favorável sob determinadas condições — os eleitores estariam habilitados a entregálos a despeito de suas relações familiares e territoriais, seriam livres para negociá-los como mercadoria, seus custos seriam reduzidos ao período propriamente eleitoral —, ao mesmo tempo e pelo mesmo motivo lhes é desfavorável. Liberados das dívidas que os prendiam a determinada rede política, desterritorializados que estão de qualquer grupo e de qualquer indivíduo, a despeito dos compromissos (falsos) que possam contrair, desvinculados das lealdades e das redes de amizade, de parentesco, do território e da dependência em geral, esse tipo de eleitor estaria à caça de quem pudesse interessar-se pelo seu voto. Vender e comprar votos, no sentido nativo da expressão, traduz uma liberação dos eleitores diante das candidaturas, e isso é reconhecido por ambas as partes intervenientes do processo.

Do ponto de vista dos eleitores não se pode considerar a mesma ambivalência. Afinal, sempre é mais favorável manter-se sob a proteção tanto mais perene quanto possível de um político. Aspiração, no entanto, atingida com mais dificuldade e raridade quando se considera que, "hoje, ninguém tem o voto de ninguém". Se os que mantêm seu prestígio por meio de seus títulos de eleitor pretendem esticar o mais possível seu raio de ação por meio da criação de um crédito e, portanto, da inalienabilidade do principal bem de que dispõem, os que alienam seus votos transformando-os em mercadorias vendáveis são os que mais distantes ficam deste objetivo. Para estes, os políticos tendem mesmo a aparecer de "quatro em quatro anos".

Uma posição intermediária ocupariam os eleitores que têm compromis- 
so mas que, sob determinadas circunstâncias, leiloam seus votos na hora da eleição, não reconhecendo a dívida que contraíram junto a um candidato. O conhecimento deste risco leva os candidatos a amarrá-los até a última hora, pois, como disse um deles, "todo cuidado é pouco". Há diversas formas de se amarrarem eleitores de quem se espera o voto. Uma delas é vigiá-los, cercá-los, encurralá-los desde a hora em que chegam ao local de votação até o momento de entrar na seção eleitoral. Como os que vêm da zona rural ou de outro município votam habitualmente próximo ao horário de encerramento da votação (apesar de muitas vezes chegarem ainda de madrugada), a fim de aproveitar todos os instantes da festa, os candidatos ao Legislativo despendem muita atenção e cuidado com eles, para além das refeições que lhes distribuem em diversos restaurantes da cidade. No passado, os candidatos concentravam o banquete em um só lugar, o que se tornou impossível por causa da vigilância da justiça eleitoral; a dispersão do eleitorado incrementa os riscos de perdê-lo para competidores.

Um outro modo de amarrar os eleitores é ameaçá-los com a possibilidade de conhecer o destino verdadeiro de seu voto. $\mathrm{O}$ mais tradicional destes meios é a anotação de todos os dados dos títulos de eleitor e o controle por meio dos conjuntos produzidos por alguns "eleitores de voto múltiplo" (Palmeira 1996). De modo que, dizem alguns políticos e alguns eleitores, é possível descobrir se uma casa votou ou não no candidato com quem tinha compromisso verificando o número de votos na urna em que seus membros votaram. Outro modo, mais atual, é constranger os que receberam favores com os novos recursos informáticos, em larga medida obscuros para a maioria dos eleitores. "Olhe, nós estamos na internet e o voto dele vai sair lá", ameaçava um candidato, conforme ele mesmo me disse. Segundo sua avaliação, "o povo engole".

Pode-se, por fim, como último modo de amarrar eleitores, fazer-lhes visitas na véspera do pleito, entregando aos considerados hesitantes somas em dinheiro carregadas na mala preta. Essas incursões, feitas na calada da noite, com todo o risco de candidaturas verem-se impugnadas por crime eleitoral, são célebres e constantemente condenadas por todas as vozes, entre elas as dos próprios políticos que se acusam mutuamente de compra de votos.

Se os eleitores são efetivamente amarrados ou não por meio desses expedientes, é impossível dizer por antecipação. Só o resultado das urnas pode responder. Assim como é de difícil verificação a possibilidade de se descobrir o voto de alguém com base na leitura dos resultados das eleições. Contra a ameaça de verem alienados os votos para os quais despenderam energia e dinheiro, os candidatos e os que trabalham para eles encontram maneiras, 
fictícias ou reais (mas que de todo modo tendem a tornar-se reais), de fixar os eleitores, de evitar o desvio de votos na última hora. É preciso vigiá-los contra a troca de chapas ${ }^{11}$ e proteger-se dos que "prometem, mas enganam" - ou seja, contra os extravios voluntários e involuntários dos votos.

O importante, neste caso, é que existem saberes nativos elaborados cujo objetivo é controlar algo a tal ponto incontrolável que é constantemente comparado a um jogo. A distribuição de recursos obedece portanto ao raciocínio do risco calculado, no qual o cálculo é apenas coadjuvante do risco. Segundo vários intervenientes, diante da promessa do voto, "os políticos arriscam". Reiteradamente, os mais diretamente envolvidos em candidaturas comparam as eleições com um jogo de azar. Investir em eleitores, neste sentido, é o mesmo que depositar dinheiro em um número na mesa de dados. Nunca se sabe o que poderá acontecer, não há garantias. A única certeza, aparentemente, é a de que é preciso arriscar, apostar. Mas como todo jogador de êxito, o candidato que se elege é geralmente considerado como o que mais sabiamente foi capaz de controlar o acaso e dominar as vicissitudes dos eleitores. Assim, ao mesmo tempo que é preciso não economizar neste período - a liberalidade crescendo na medida em que se aproxima o grande dia -, há que "saber gastar". Do contrário, costuma-se dizer, "pode ter um milhão e não ganhar"12.

A junção e a repetição constantes das duas fórmulas ("saber gastar" e "pode ter um milhão e não ganhar") mostra como, do ponto de vista dos intervenientes, a compra de votos não garante vitória, e os recursos materiais não são, ao menos não exclusivamente, a chave que abre as portas para os cargos eletivos. Não se vota apenas nos que fornecem recursos. Vota-se naqueles que os fornecem, mas que são conhecidos. Por esse motivo, cada candidato leva consigo nas viagens de campanha pessoas conhecidas nas regiões que visitam. Seria inusitado pedirem-se votos, distribuindo bens, dinheiro, serviços e promessas a uma população desconhecida. Perplexa, ela os receberia sem contrair nenhuma dívida como contrapartida. Entre outras coisas, porque é admitido localmente que se aceitem presentes de outros candidatos e se vote naquele com quem se tem compromisso. Por outro lado, o que é reprovado moralmente é o pedido - no qual vai embutida a promessa de votos - seguido da traição, muitas vezes recheio na própria promessa. O dinheiro, portanto, sob suas mais diversas formas, não transforma necessariamente o processo eleitoral em um mercado. Tal processo,todavia, não deixa de manifestar-se como tal ao mesmo tempo em que aparece como um sistema de dons e contra-dons. Existe, assim, um intercurso constante entre os sistemas de dons e o de mercadoria, entrelaçados por circulações que sobrepõem os dois conjuntos e diluem as fron- 
teiras entre eles. O dinheiro, recebido contra a entrega ou a promessa do voto, é tomado como elemento de uma transação mercantil ou de dom, segundo as relações estabelecidas entre o eleitor e o candidato ou seu representante; segundo, também, o momento e a maneira em que é dado e recebido, sendo que muitas vezes a distinção é difícil e confusa mesmo para os intervenientes diretos e para a justiça eleitoral.

Assim, tanto o dom em dinheiro é desmercantilizado, quanto o de um favor é mercantilizado e objeto de uma troca toma lá, dá cá. Por exemplo, um eleitor justificou seu voto em um candidato por ter recebido dele dez reais quando precisava muito desse dinheiro. Os dons desmercantilizados de dinheiro costumam situar-se sob estas circunstâncias. Quanto aos favores, eles podem ser encerrados em uma relação puramente troquista, em que dívida e crédito são cancelados assim que o voto é depositado na urna. Após ter-se tornado clandestino e fugitivo da justiça, um sitiante dependeu de um juiz para que seu processo fosse arquivado. Diante de tal favor, e da diferença hierárquica que o separava de um magistrado, convenci-me de que toda a sua família votava em seu antigo benfeitor. Desfiz meu equívoco ao perguntar a eles em quem iriam votar. Disseram-me que tinham votado nele logo de sua primeira candidatura e tinham considerado paga a sua dívida ${ }^{13}$.

\section{O crédito, a dívida e o tempo}

A reputação de um eleitor, ou de sua casa, determina o tipo de relação que ele poderá estabelecer com um candidato, pois baseado nela está o crédito atribuído à palavra empenhada. Tal crédito é capaz de prolongar sua condição de eleitor e ampliar no tempo os recursos que dela poderá retirar. Assim, os eleitores não são apenas alvo de endividamento, mas detentores de um crédito que aumenta de acordo com a fidelidade demonstrada e com a história da ligação entre eles e os políticos em quem votam. E os eleitores sabem-se credores dos candidatos que ajudaram a eleger. É a eles que recorrem em momentos de dificuldade e não hesitam em abandoná-los imediatamente após verem frustradas as suas expectativas ${ }^{14}$.

Em contrapartida, ao descrédito correspondem a brevidade e a instantaneidade da relação bem como o encurtamento dos recursos recebidos até o seu paroxismo, a troca do voto pelo dinheiro recebido a caminho da urna relação esta caracterizada localmente como venda e alvo de avaliação negativa. Portanto, o tempo existente entre os atos de dar e retribuir, várias vezes enfatizado pelas teorias da reciprocidade (p.ex., Malinowski 1978 [1922]; Mauss 1993 [1925]; Bourdieu 1980; 1996; Gouldner 1960), não entra em cena nestes $\operatorname{casos}^{15}$. Não é ocioso notar que o descrédito vale de parte a parte. 
Um eleitor pode ser considerado um "sem-vergonha" pelo candidato e viceversa. O primeiro paga o preço pelo descrédito no pouco acesso que tem aos recursos e na escassez de prestígio, ao passo que o segundo, nas falsas promessas de voto que recebe ${ }^{16}$.

Para um eleitor desacreditado, o voto perde poder de barganha, peso e valor. A venda do voto indica, assim, por um lado, a perda de seu valor de uso, tal como é por vezes expresso pelos intervenientes. Se para nada poderão usá-lo, é melhor vendê-lo e com ele obter, ao menos, algum dinheiro. De resto, é possível ver aí uma vantagem surpreendente: a de retirar de algo sem utilidade certo lucro. A perda do valor de uso do voto decorre também do descrédito dos eleitores nos políticos e na atividade política como um todo, partilhada em diferentes graus por todos os intervenientes da disputa eleitoral. Mas o desejo expresso de vender o voto pode decorrer do reconhecimento de seu imenso valor, não para o eleitor, mas para o candidato que o pede. Um voto devia custar muito dinheiro, disse um eleitor, acrescentando que não se devia dar um voto por menos de dois mil "contos". Cabe então inferir a capacidade dos eleitores de uma dupla avaliação. O que para ele não tem valor, para outros é valioso. Através deste jogo de perspectivas ele se acha mais uma vez preso nas teias do jogo eleitoral, do qual não consegue escapar.

Nada disso impede, entretanto, a existência de dons aparentemente gratuitos, como diriam Godbout (1995; e Caillet, 2000 [1992]) e os demais membros do M.A.U.S.S17, no sentido eleitor-candidato. Vota-se por consideração, por querer bem, pela amizade e pelas diversas modalidades de parentesco que diminuem a "distância social" (cf. Sahlins 1976 [1965]), sem outro interesse declarado ${ }^{18}$. Na verdade, a "distância social" costuma aumentar quando falta circulação favorável de recursos, atenções, consideração, enfim, atribuição de prestígio. É recorrente candidatos dos níveis federal e estadual negligenciarem seus municípios de origem em virtude da crença em um tipo de voto, por assim dizer, natural de seus munícipes, acreditando-se garantidos pela fidelidade dos eleitores. Pode ocorrer de perderem eleitores e parte significativa de um colégio eleitoral a médio e longo prazos, segundo a avaliação de intervenientes, por causa dessa atitude.

Conforme lembra Veyne, "os interesses dos eleitores são múltiplos, e os meios que os candidatos têm de se tornar populares são, conseqüentemente, numerosos" (Veyne 1976:396). Alguns candidatos esforçam-se para transformar em dons gratuitos os recursos disponibilizados aos virtuais eleitores. Procuram dar aos favores e bens uma aparência desinteressada, desvinculada do voto que esperam receber. Assim procedendo, acreditam criar no eleitor o mais autêntico e sincero sentimento de gratidão, laço ines- 
capável entre as duas partes, método pelo qual estará dissolvida qualquer suspeita de troca direta. Produzirão, por este método, um crédito de longo prazo, possivelmente indelével nas memórias de seus eleitores. Endividados sentimentalmente, encontrarão um equivalente para saldar a dívida de uma internação, de um enterro, de um exame, de um remédio fornecido por alguém que sequer foi solicitado. Um dos candidatos com quem realizei a pesquisa diz não esperar que se lhe peça algum favor. Tenta descobrir as necessidades de pessoas que não ousam tentar preenchê-las por meio de pedidos, obrigando-se a lançar mão da espionagem. De posse da informação, ele dá o que for necessário sem tocar no assunto fulcral da política. A transação é feita no plano tácito, sem intervenção de cobranças, exigências, demandas e pressão direta. Do ponto de vista nativo, esta é a maneira legítima de obterem-se e distribuírem-se votos e recursos. Ela não é, todavia, a mais freqüente. De direito, mas nem sempre de fato, ela, embora não encete, insufla as relações de dívida e crédito de parte a parte. Reforça, sem contudo desmanchar a relação de poder inversa, a submissão do dono do voto ao dono do recurso, amplia a influência do candidato nas decisões da pessoa ou da casa recebedora do benefício, marca a dupla captura resultante do acordo, sublinha as relações assimétricas entre as partes . Doravante, repito, de direito, o eleitor deve ao candidato (Heredia 1996:64), mas espera dele como contrapartida o compromisso de velar por ele, "durante os quatro anos" e não apenas na época da política. De modo que um candidato assume o encargo de fazer fluir recursos-favor, ao passo que um eleitor encarrega-se de, no momento em que for acionado, fazer fluir recursos-voto.

\section{Os sentidos do dinheiro}

A monetarização da disputa eleitoral é ao mesmo tempo diabolizada e positivamente valorizada. Diabolizada por desfazer os laços de lealdade e solidariedade considerados como o norte dos antigos pleitos; por produzir um tipo de eleitor traidor, explorador, seboso, independente; por desqualificar completamente os candidatos eleitos, já que, ao fim e ao cabo, "agora é tudo dinheiro"; por transformar a política em alvo do escárnio e do ridículo. Positivamente valorizada porque sustenta, aos olhos dos eleitores, o seu prestígio, mesmo por um instante fugaz; porque, ao menos nessa época, podem obter recursos inatingíveis em outras; por torná-lo objeto do zelo, da gentileza, da generosidade, da atenção, de quem cotidianamente nem sequer "me dá um bom-dia", com quem "você vai falar e ele vira a cara". Diante desse quadro, muitos se aproveitam e destratam abertamente certos candidatos, perguntando a eles 
quem são e por que estão se dirigindo a eles. O embaraço sofrido por esses candidatos provoca uma campanha silenciosa na zona urbana de um dos municípios, em que as propagandas e os pedidos de votos são jogados debaixo das portas durante a noite e cochichados ao pé do ouvido.

Além disso, o dinheiro ligado à política assume, segundo as avaliações nativas, uma dupla característica. Ele é signo do atraso e do clientelismo. Mas é também o índice de progresso e desenvolvimento. A campanha vitoriosa do candidato de oposição à prefeitura de um dos municípios pesquisados baseou-se no lema "o tostão contra o milhão". Em jingles e anedotas, aludia-se ao poder econômico do deputado federal que apoiava a situação nesse município, opondo seu modo de fazer política ao atual esclarecimento do povo, ao qual "não dá pra comprar, não, com vinte [reais] dentro do pão" (alusão ao método de entregar dinheiro aos eleitores utilizado, segundo se diz, pela esposa daquele deputado, pilhada no ato pela justiça eleitoral no dia das eleições de 1998), desde que o povo "aprendeu votar". Assim, a música aconselha o deputado a "dar ré no avião" e diz-lhe que "arrume a mala aí", pois, para ele, "no sertão não tem mais lugar". Eis aí, portanto, a acusação aguda de trazer debaixo do braço a população sertaneja por meio de uma política inadequada para os tempos em que vivemos.

Acusado de levar para aquela campanha um milhão de reais, o deputado respondeu que não trazia um, porém cinco milhões, para desenvolver o município, desvinculando o dinheiro da compra dos votos e ligando-o a promessas de campanha. Ao mesmo tempo, rebateu as acusações na mesma moeda, acusando os adversários que se afirmavam pobres de recolher fundos junto aos mais ricos comerciantes do município, e os criadores de gado de venderem boiadas para alimentar a campanha "do tostão contra o milhão". Acusou-os também de oligarcas, baseado na genealogia do candidato a prefeito, cuja família reinara absoluta no município durante o Segundo Império e parte significativa da Primeira República. Acusou-os igualmente de coronéis que manteriam, "debaixo de ordens", currais eleitorais em diversos distritos ${ }^{19}$.

Se, conforme afirma Palmeira (1992:29), o uso excessivo dos recursos econômicos é reprovado pelos intervenientes, é impossível igualmente desconhecer que ele também os seduz. Não é raro que correligionários de um deputado federal o distingam como um dos homens mais ricos do país, tentando promover assim a sua imagem como bom político e bom homem, capaz de ter obtido excepcional êxito no campo financeiro. A mesma ambivalência marca muitos eleitores quando se trata de receber dinheiro vivo em troca de votos. Ao mesmo tempo que rejeita o dinheiro, o povo declara por vezes desejar que "lhe toque a mala preta". 
A imputação da fortuna dos políticos à corrupção pode ser tolerável moralmente, cumpridas certas condições. Embora o roubo seja uma atividade severamente condenada, o desvio de verbas públicas, ainda que também vergonhoso, conta com alguma complacência, na medida em que serve para gerar favores, para ajeitar os parentes e os amigos. Desvinculado da noção inequivocamente condenável do furto, aquilo que, de certo ponto de vista, constitui malversação do dinheiro público, pode ser tanto positiva, quanto negativamente avaliado.

\section{Circulação e produção}

Nem tudo se esgota na circulação, pois isso suporia que os eleitores estão todos prontos e os recursos, todos disponíveis. Uns e outros precisam ser produzidos, cada um a sua maneira. Nem uns nem outros são frutos maduros pendendo de galhos baixos ao alcance da primeira mão que os arranque. A expressão fazer eleitores, muito usada pelos cabos eleitorais ou assessores, como preferem alguns deles, traduz bem a necessidade de arregimentar indivíduos ou coletividades. Fazem-se eleitores, por exemplo, transferindo-os de seção eleitoral, em certos casos de município a município. Diante de certas vantagens prometidas, alguns favores concedidos, ou candidaturas de parentes, costuma-se abandonar um município em favor de outro. Isso é mais freqüente entre os habitantes de zonas fronteiriças. Por esse motivo é constante a preocupação com o alistamento, ou seja, o recadastramento eleitoral. Podem-se perder eleitores caso se descure das suas necessidades. Por outro lado, a atenção a elas pode provocar verdadeiras romarias em dias de eleição: gente que vem de longe para votar em certos municípios onde conservam seus títulos de eleitor.

Outro método de fazer eleitores é manter fiéis os descendentes das casas que tradicionalmente apoiaram um grupo ou uma facção política. Para isso, não basta alistar, convém conferir prestígio, por exemplo, sob a forma do mais valioso dom, a forma mais adequada e segura de produzir um eleitor: dar empregos. Mas, mesmo aí, há sempre que arriscar. Isso porque as redes de solidariedade são de tal modo complexas, os favores e os pedidos circulam em tantas direções, que, por vezes, um eleitor pode não saber em quem votar. É bem verdade, como mostrou Palmeira (1992:29-30; 1996:51-52), que em eleições do tipo aqui descrito não há eleitores indecisos: os há em disponibilidade, em oposição àqueles que têm compromisso. Mas pode haver indecisão como conseqüência de se deverem favores de pesos semelhantes a diversos candidatos, como sucedeu a uma eleitora. Um político conseguiu um cargo comissionado para sua filha, outro dedicou-se incansavelmente, 
como médico, durante a doença do pai, além de ter sido amigo de primeira hora de seu filho. O dilema desta interveniente é terrível para ela. Tudo o que pode fazer é uma escolha interna, silenciar seu voto ou garantir aos dois que votará neles. Ela, como eleitora, é tanto produzida pelas atenções de que foi alvo, quanto essas atenções são recursos produzidos por meios diferentes.

Os recursos tampouco estão todos disponíveis, resultado do orçamento municipal originado na partilha do orçamento federal, o que põe entre parênteses as teses que baseiam a patronagem no monopólio sobre as fontes de recursos (cf. Avelino 1994:229; Eisenstadt 1984:101), assim como as que afirmam ser determinante o monopólio de posições de importância crucial para os clientes (Eisenstadt e Roniger 1984:49 e, especialmente, 168 ${ }^{20}$. A ausência de monopólio sobre os recursos e a disputa perpétua sobre seu controle vêm ao encontro da inflação dos custos de cada voto, segundo cálculos de candidatos, uma vez que há competição mais ou menos livre entre eles. Ademais, muitos dos recursos-favor são produzidos pelos próprios candidatos segundo suas habilidades e suas atividades profissionais, o que inviabiliza qualquer monopolização. Isso explica, em certa medida, o êxito de médicos, advogados, assistentes sociais e enfermeiras, cuja representatividade é alta nas câmaras municipais. Os favores que estão aptos a disponibilizar diluem aparentemente o caráter mercantil da relação candidato/eleitor, atenuando a "crucialidade do momento eleitoral" (Avelino Filho 1994:30). Algumas pessoas baseiam nas brechas abertas pela escassez generalizada de recursos o seu possível sucesso na política, embora muitos deles superestimem suas possibilidades e por isso sejam considerados ingênuos, crentes na obrigatoriedade da retribuição ${ }^{21}$.

A produção e obtenção dos recursos a serem postos em circulação durante a campanha eleitoral é tanto obra de engenharia quanto de bricolagem. Como nem todos os candidatos estão conectados às fontes verticais de serviços e bens, muitos deles devem produzi-los por seus próprios meios, em certos casos impossibilitados que estão de desembolsar grandes quantidades de dinheiro. Por isso, necessitam muito mais de sua história pessoal e familiar que os demais. Alguns deles, como foi dito, são enfermeiros, algumas são professoras, outros são ligados ao trabalho social, outros ainda a pastorais da igreja católica. Em certos casos, são líderes comunitários aventurando-se pela primeira vez na vida da política profissional. Como único capital eleitoral, dispõem dos serviços que prestaram às pessoas, do crédito, da gratidão, da amizade, da confiança que crêem ter nelas despertado.

Na outra ponta, há candidatos intensamente conectados aos níveis superiores da política e que, portanto, obtêm muitos recursos represados, 
tendo em suas mãos a possibilidade de abrir ou fechar a comporta, canalizando suas trajetórias. Mesmo aí, a criatividade é, segundo me pareceu, espantosa. Tudo pode ser convertido, virtualmente, na esperança de votos: a supersafra de melancias (distribuídas nos sítios), terrenos urbanos, medicamentos, tomografias, encomendas de serviços e materiais no comércio, informações, gentilezas, etc. Diante dos recursos à disposição da prefeitura, os correligionários do prefeito disputam entre si as suas benesses. Elas se traduzem em dinheiro para a campanha, por certo. Mas também em favores. Na casa de um candidato a prefeito, diante de suas reclamações, perguntei se o deputado estadual que o apoiava não o estava ajudando. Ele disse que sim. Não dera dinheiro, mas dera rede de eletrificação em seis sítios, diversos poços amazonas, 500 tomografias, somando $14 \mathrm{mil}$ reais. Segundos os seus cálculos, o total equivaleria a algo entre 40 e 50 mil reais. E mesmo assim, seguiu ele, tal montante não equivale, em força eleitoral, a esses serviços. Ademais, em sua avaliação, quando o prefeito recebe dinheiro, "fica na mão do deputado", sendo depois abandonado por ele até as eleições, quando este vem pedir àquele, sem nada dar, um número preestabelecido de votos. Fornecendo serviços e favores, ele, enquanto prefeito, poderia pedir cada vez mais melhorias para o município

\section{Um olhar aproximado sobre a democracia representativa}

O que se pode retirar deste breve relato? Duas conclusões aparentemente opostas: 1) que o dinheiro, segundo este interveniente, vincula mais que os favores; 2) que os favores valem mais que o dinheiro. E por quê? Deduzse, então, que os favores, ao contrário do dinheiro, criam vínculos mais profundos entre o político que dá e o eleitor que recebe. Se é assim entre essas partes, por que não seria assim entre eleitores e candidatos quando os eleitores são os prefeitos e os candidatos são os deputados? Porque o dinheiro que entra serve para o prefeito, ao passo que os exames, eletrificação, etc., dinheiro convertido em favores, tornam o prefeito apenas um veículo entre aquele que dá e aquele que recebe. O favor concedido não o tem como alvo final, mas como transporte. Os créditos são assim partilhados entre prefeito e deputado junto a um eleitorado futuramente satisfeito e confiante em ambos. Mas, na lógica dos eleitores, seguindo ainda o raciocínio do prefeito mencionado, as benfeitorias refletem o seu prestígio junto a autoridades do nível estadual da política pernambucana. Produzem a imagem de alguém capacitado e habilitado a ajudá-los; transmitem o sentimento de força. 
Do ponto de vista desse mesmo candidato, que viria a se tornar prefeito, a entrega de favores desperta gratidão. Isso, segundo a avaliação de boa parte do eleitorado, deu-lhe a vitória no pleito, garantindo $80 \%$ dos votos válidos, contra o candidato da situação. Sem esquecer que uma candidatura é necessariamente segmentada ${ }^{22}$, sua atuação como médico do Sindicato dos Trabalhadores Rurais, assim como a figura histórica de seu pai, grande assistencialista e tradicional cabo eleitoral de políticos de diversas esferas, criaram em torno dele enorme afeição popular. As pessoas o descrevem como um médico incansável e como uma pessoa humilde. A medicina, a simpatia, a humildade e a educação no trato com os habitantes das áreas rurais renderam-lhe a possibilidade de produzir eleitores ao mesmo tempo em que criava os seus recursos eleitorais intangíveis. Estes, embora não suficientes para garantir vitória, são a base na qual se apóiam os recursos tangíveis. Essa convicção é ratificada pelo prefeito no momento em que afirma sua preferência pelos favores em detrimento do dinheiro.

Como, então, compreender os processos que levam pessoas a conquistarem cargos eletivos se nada parece seguro, se nenhuma grande previsão parece possível, se, enfim, segundo o ponto de vista dos intervenientes, tudo o que podem fazer é arriscar? Embora deva-se reter esta face quase aleatória do processo eleitoral, de tudo o que foi dito aqui é preciso conservar também as regularidades existentes, retesadas constantemente pelo risco, pela traição, pela mentira.

As críticas sofridas pelos que negociam votos tornam a negociação uma prática semiclandestina, salvo às vésperas do pleito, quando, conforme se repete constantemente, o feio é perder ${ }^{23}$. A circulação recurso-voto/recurso-favor não é negativamente valorizada porque é um componente, e não um desvio, do processo, sem o qual ele perde a integralidade de seu sentido para os intervenientes. Assim, a democracia representativa, por um lado, tal como é compreendida localmente, é o modo pelo qual determinados recursos mudam de lugar e outros são criados para satisfazer necessidades prementes ou não. O povo é, dessa maneira, atravessado por uma espécie de poder que lhe cabe e que aumenta e diminui segundo as proximidades dos eventos considerados políticos, mas também segundo a proximidade de cada um com a política. Esse poder é sentido pelos intervenientes, independentemente do lado em que se situam nesse jogo. Os políticos, sentindo a pressão do povo, temem contrariá-lo, devido exatamente a sua posição. O povo, ciente da força que exerce sobre os que de seus votos dependem, procura tirar proveito da situação, seja através de pressões silenciosas, seja por meio de apelos ruidosos. Não obstante, enfim, o peso da dominação social nos municípios aqui enfocados, provavelmente nenhum 
de "nós", eleitores individuais afastados da esfera político-partidária, jamais teve um contato tão aprofundado com a democracia representativa quanto a maior parte das populações rurais e urbanas cujo comportamento eleitoral este artigo propôs descrever.

No entanto, constatar o que a democracia representativa é não impede a formulação do que ela deveria ser. Os intervenientes têm idéias claras do que é votar consciente e de quem são os melhores candidatos. O voto consciente, é bem verdade, não se identifica ao voto ideológico. E os melhores candidatos não são sempre os políticos bons; muitas vezes eles podem ser os piores ${ }^{24}$. Isso porque entende-se por "político bom" aquele que "não nega nada que o povo pede", o que geralmente não corresponde à prática dos localmente avaliados como os melhores candidatos. Por isso estes, sabidamente, têm pouca chance de vencer eleições. Eles não fazem a democracia funcionar como se deve, não são bons agentes de circulação e produção de recursos.

"Aqui só o que vale é o dinheiro". A ladainha é repetida por todos os excandidatos algum dia derrotados. Em sua maioria pertencem a partidos classificados como de esquerda e que se recusam a entrar no jogo da reciprocidade eleitoral, ou não dispõem dos meios apropriados para isso. Mesmo estes, entretanto, não desprezam absolutamente a circulação de recursos, caso alimentem verdadeiramente a esperança de verem-se eleitos. Muitas vezes os recursos recebem uma tinta ideológica ou de caráter missionário.

"O eleitor aqui tá mais caro que em Recife", queixam-se outros, enquanto contabilizam, amargos, os gastos de suas campanhas. Se o uso excessivo do dinheiro e de outros recursos - que para os bolsos dos candidatos acabam muitas vezes transformando-se em dinheiro - é reprovado tanto legal quanto moralmente, ele o é muito mais em nome da nostalgia de um tempo passado, quando, considera-se, votava-se por devoção ao chefe e ao patrão, por fidelidade à facção e à família, por tradição e obediência filial. Lamenta-se o fato presente de se ter de convencer os eleitores a votar em um candidato em vez de simplesmente indicar-lhe seu nome conforme, diz-se, ocorria outrora.

A outra parte, a dos eleitores, consciente de sua situação, procura, por um lado, desfrutar do período em que é alvo das atenções gerais dos candidatos, ou seja, a época da política. Por outro, esforça-se por esticar tanto quanto possível no tempo a sua condição de eleitor e o prestígio que lhe é conferido por meio dela. Um movimento cujo efeito desejado parece ser o de manter inalienável exatamente o que deve ser posto em circulação: o seu voto. Ou seja, pretende-se, segundo penso, realizar, no campo eleitoral, o paradoxo do keep while giving (Weiner 1985; 1992). Procura-se prolongar o valor de uso de seu voto de várias maneiras, entre elas produzindo um conjunto deles, tornando-se um eleitor de voto múltiplo. Estender no tempo 
o valor de seu voto e seu prestígio através deste expediente talvez corresponda a tornar-se político, uma vez que se prolonga, junto, o "tempo da política" (Palmeira e Heredia 1993); isso quer dizer mudar a "natureza do agenciamento" (Deleuze e Guattari 1980:546-552) ${ }^{26}$.

Por sua vez, os que fracassam nesta tentativa dispõem ainda da possibilidade de alienar seus votos em troca de bens ou de dinheiro. A troca direta do voto por dinheiro, ao contrário dos bens, recebe críticas radicais de todos os intervenientes, inclusive muitos dos que o dão e o recebem, como signo inequívoco de alienação de voto - uma vez que a presença do dinheiro em si pode não denunciar tal relação (ou ausência de relação). Esse tipo de transação encerra-se no momento mesmo da entrega do voto, sem lançar suas raízes no futuro e é independente das raízes criadas no passado. Na verdade, o passado influi ao pregar em um eleitor a reputação de desacreditado, pecha que o desabilitará a estabelecer laços duradouros com políticos e candidatos.

Para encerrar, gostaria de ressaltar que essa relação com a democracia representativa não é específica do Sertão de Pernambuco, como tampouco do Brasil27. Além disso, não se restringe aos municípios do interior, nem às esferas menos importantes do poder. Alguns estudos mostram como tais práticas funcionam nos grandes centros do poder (p.ex., Bezerra 1999) e em países fundadores e difusores do ideal democrático (p.ex., Jankowski 1991). Apenas, por efeito de uma concepção de política derivada da tradição e da pragmática, as práticas aqui descritas podem ser observadas à flor da terra, em vez de serem camufladas, como ocorre em outras partes.

Recebido em 12 de abril de 2004

Aprovado em 6 de outubro de 2004

Jorge Mattar Villela é pós-doutorando no Departamento de Antropologia da USP. E-mail: <villelajorge@ig.com.br> 


\section{Notas}

${ }^{1}$ MacCormack (1976:89) queixa-se do significado "auto-evidente" e da sinonímia no uso dos termos "reciprocidade", "recíproco", "dom", "contra-dom" e "troca".

${ }^{2}$ Por exemplo, Vianna 1987 [1949]; Duarte 1966 [1939]; Leal 1997 [1949] e Queiroz 1976, para os textos clássicos, e uma série importante de outros autores dentre os quais destacaria Graham 1997. Diversos estudos devotados ao clientelismo deram especial atenção às relações de reciprocidade, tais como Scott 1977, Silvermann 1977 - que destaca o fato de que os laços entre patrão e cliente, no sul da Itália, são desfeitos caso o primeiro não seja capaz de dispensar favores —, Kenny (1977:356), para quem "cliente" é alguém que mantém com um patrão "relações de reciprocidade", e Wolf 1966, embora este último ressalte a importância dos laços afetivos mínimos que garantem "a promessa de futuro apoio mútuo" (1966:16). Uma das exceções à regra é Eisenstadt e Roniger (1984:164), que atenuam o papel da circulação de favores em proveito das relações sociais prévias, já que uma das características básicas que atribuem às relações patrão/cliente é a diferença hierárquica entre as partes, em que pese sua hesitação entre uma e outra coisa: para eles, tais relações são "modelos diferentes de estruturar o fluxo de recurso e troca e interação interpessoal na sociedade: como diferentes modo de troca generalizada". Outras exceções são Chubb (apud Avelino Filho 1994:229), para quem "a relação tem valor por si própria e as trocas de favores, a despeito de poderem fortalecê-la, não são essenciais para sua manutenção" e, de um modo ligeiramente diferente, Grynszpan, ao considerar que a patronagem caracteriza-se muito mais pelo deslocamento de pessoas no espaço social do que pela regulação de fluxos de bens que propiciaria (Grynszpan 1990:89).

${ }^{3}$ Dados do IBGE e TRE/PE até as eleições de 2000. Segundo os dados para 2002, os eleitores são, também aproximadamente, 12 mil, 48 mil e 17 mil. As aproximações, assim como a omissão dos nomes dos municípios, devem-se à necessidade de anonimato dos locais e dos habitantes que generosamente depositaram confiança em meu trabalho e em minha presença, aos quais sou imensamente grato.

4 Todas as palavras em itálico, salvo expressões em língua estrangeira, pertencem ao vocabulário nativo.

${ }^{5}$ Algo semelhante se passa com outros momentos, como, por exemplo, a época dos tribunais e o tempo das brigas. 
${ }^{6}$ Por mercado, aqui, deve-se entender um tipo de relação comercial, baseado na troca despersonalizada e direta que se encerra na própria transação. Ele corresponde, também, a uma transação pela qual o voto é tornado mercadoria pura, sem a existência de dons. Como se verá, o mercado só aparecerá neste texto como um esforço analítico, uma virtualidade que, ao se realizar, aparece já como um misto de mercado, redistribuição e reciprocidade.

7 Também Landé (1977:xxiv) discute o problema da equivalência nessas bases, sem contudo usar a mesma terminologia.

${ }^{8}$ De resto, Lefort havia já desde há muito ressaltado a importância da liberdade no interior mesmo do caráter "rigorosamente obrigatório" das transações sugerido por Mauss. Para Lefort, essa liberdade está contida na idéia de crédito e de confiança de que "o dom será feito com interesse embora nenhum compromisso o garanta" (Lefort 1979 [1951]:24).

${ }^{9}$ Em uma obra hoje clássica, Bohannan e Dalton (1962) mostram as características das sociedades sem mercado, com mercado periférico e em que o mercado é o princípio dominante, segundo fontes de subsistência, formação de preços de bens e serviços, uso do dinheiro, mercado externo, etc. Quase todas as características encontradas em quase todas as condições existem no contexto social das eleições por mim observadas. Assim, essa situação mista poderia ser identificada à situação intermediária das economias com mercado periférico. No entanto, seria no mínimo arriscado considerarem-se os municípios do sertão de Pernambuco, hoje em dia, como economias de mercado periférico. É bem verdade que Sahlins (1976 [1965]) prevê a possibilidade da fusão entre reciprocidade e redistribuição (pooling), já que este último é um sistema de reciprocidades, embora as relações sociais exigidas para cada um dos tipos de transação sejam diferentes. Como se sabe, o conceito de redistribuição concebido por Polanyi (seguido por Sahlins) supõe unidade social e centralidade, ao passo que a reciprocidade demanda simetria e dualidade. Um texto crítico da clivagem essencial entre sistema de dons, do lado do orientalismo, e de mercado, do lado das sociedades ocientais (Carrier 1995:92-94), mostra como relações típicas de mercado não cancelam o sistema dos dons.

10 Para uma discussão sobre a circulação de recursos-favor contra recursos-voto e vice-versa e da questão do prestígio, ver Villela e Marques 2002.

${ }^{11}$ A troca de chapas consiste em substituir, sem que os eleitores se dêem conta, o número de seu candidato pelo número do cabo eleitoral que o aborda na boca da urna. A chapa em questão refere-se a gabaritos que eram colocados sobre as cé- 
dulas na hora da votação. O expediente da troca de chapas deve ter perdido sua força com o artifício das fotos nas novas chapas (que em outros lugares são conhecidos pelo nome de santinhos), mas é ainda temido pelos candidatos.

$12 \mathrm{O}$ jogo ligado às eleições não aparece apenas como uma alusão. Aposta-se em certos casos somas avultadas. Os apostadores depositam o dinheiro nas mãos de uma testemunha e, no maior dos municípios pesquisados, há os que preferem, segundo me foi dito, registrar a aposta em cartório. Os que apostam muitas vezes estão ligados aos candidatos em que depositam sua fé e o fazem segundo diferentes modos. Pode-se apostar apenas na eleição majoritária: 1) no nome do vencedor; 2) na diferença de votos que o separará do segundo colocado; 3) no total de votos que obterá. Pode-se apostar nas proporcionais: 1) se será ou não eleito; 2) no número de votos de um determinado candidato; 3 ) em sua posição na lista dos eleitos. Essa é portanto uma outra modalidade que faz circular dinheiro neste período e que reflete o interesse geral pela política.

${ }^{13}$ Como notou Gregory (1982:48), as transações com dons e contra-dons e as transações com mercadorias têm formas diferentes de cancelarem as dívidas. Ele observou também que "não é o atributo natural da coisa trocada que determina se uma troca é feita sob a forma de dom ou de mercadoria. Dinheiro pode assumir a forma do dom em certos contextos sociais [...]" (1982:47). Para o caso das trocas de dons, ele fala de "desequilíbrio alternado" (1982:52). Ainda a respeito do cancelamento da relação credor/devedor, Gregory lembra que, para Marx, a troca de mercadorias supõe "estado de independência" entre os que transacionam. Por seu lado, a troca de dons supõe "estado de dependência recíproca" (1982:42).

14 Para uma discussão acerca do voto como amortização das dívidas contraídas pelos eleitores junto aos candidatos, ver Palmeira 1992:28 e 1996:47, e Heredia 1996:62-64.

${ }^{15}$ Para Gouldner (1960:174), além de ser um fator de acumulação para a retribuição, o tempo é também o da gratidão, da obrigação e da dívida. Retribuir instantaneamente é, portanto, impedir a criação destes vínculos. Para Bourdieu (1996:13-14), o dom constitui o tempo, o intervalo entre as duas ações, produzindo uma dominação legítima; ao passo que a devolução imediata distingue a troca de dons do toma lá, dá cá.

${ }^{16}$ Pode-se notar aí a constituição de uma política dos eleitores, algo próximo do que Bailey (1971:3) chamou de "política da vida cotidiana".

${ }^{17}$ Mouvement Anti-Utilitariste en Sciences Sociales. 
${ }^{18}$ A situação do parentesco é complexa demais para ser exposta aqui. Cabe porém observar que seus laços são reconhecidos e ignorados segundo determinadas circunstâncias, entre elas a política e a territorial, tanto quanto pelos laços de sangue e afinidade. Para uma descrição analítica do parentesco no sertão do Vale do Pajeú, ver Marques 2001 e 2002, e Vilela 2003.

${ }^{19}$ A propósito da retórica social versando sobre chances de vitória e da explicação da derrota de um candidato proferido pelo discurso nativo, e sua dupla face, em uma eleição municipal, ver Goldman e Silva 1998. Também Palmeira (1992) insiste em um aspecto da reciprocidade em que o que é posto em circulação são promessas eleitorais e acusações mútuas.

${ }^{20}$ Nicholas (1968:301-2), por sua vez, afirma que a luta pelo controle dos recursos, humanos ou materiais, voltados para a ação política, é o próprio objetivo político. É verdade que os estudos das relações patrão/cliente enfatizaram tão freqüentemente a luta pelo controle dos recursos que se torna injusto destacar um ou um conjunto de autores. Para uma breve panorâmica ver Weingrod 1977. Para uma defesa deste ponto de vista ver Scott 1977.

21 Talvez valha lembrar aqui que Weiner (1992:149-150) critica a crença no fundamento da devolução como motivação última do dom. Ele é percebido apenas, diz ela, em relação ao retorno que evoca. Para ela, o que gera confiança na devolução é o poder irradiador de manter posses inalienáveis fora do circuito da troca.

22 No caso das eleições municipais, os segmentos são formados por vereadores e subgrupos políticos no interior mesmo da candidatura à majoritária, cada um lutando para obter mais recursos, mais prestígio e mais votos que os demais, provocando assim uma disputa interna simultânea (e freqüentemente mais acirrada) à externa, com os adversários de outros partidos. A respeito da segmentaridade na política ver Goldman 2000 e 2001.

${ }^{23}$ Nos mesmos termos, Garrigou (1992:136-7) fala dos políticos franceses no século XIX: "A primeira preocupação dos candidatos e de seus partidários não era respeitar legislação eleitoral, mas ganhar a eleição". A respeito da valoração ambivalente da "compra de votos", diz Goldman: "[...] a compra e venda de votos aparece como elemento de estratégias discursivas variadas: pode-se condenar alguém por praticá-la, mas pode-se igualmente invocá-la a fim de justificar posições às vezes difíceis de confessar" (2001:326). A respeito da oposição entre "regras morais" e "regras pragmáticas" durante as disputas políticas, segundo as quais o valor da vitória tem precedência sobre os princípios morais e também sobre as "regras jurais", 
ver Nicholas 1968:304-305. Sobre as regras normativas em oposição às regras pragmáticas que também servem para romper regras, ver Bailey 1968:293. Herzfeld (1996) mostra como as desculpas possibilitam a justificativa de atos subversivos às regras locais e à obediência à ordem do Estado-nação e vice-versa, notadamente onde estes são conflitantes com aqueles. Relativamente à labilidade conferida pelos shifters, mostra que o conteúdo moral é constantemente negociado no interior da comunidade, sendo que conceitos como honestidade e masculinidade não são dados. Não há, portanto, para os aldeãos do caso que estuda, comportamentos que sejam avaliados como bons ou maus a priori.

${ }^{24}$ A respeito dos problemas enfrentados por um prefeito que tentou suprimir o "lado social" de seu governo, tornando-se "bom prefeito, mas mau político", ver Palmeira 2000:13.

${ }^{25}$ Goldman (2001) defende a modulação do "tempo da política" de acordo com o grau de envolvimento na atividade política: intermitente para os eleitores; permanente para os profissionais.

${ }^{26}$ As pesquisas de Goldman mostram como a política pode ser entendida muito mais como "atividade" do que como "domínio". A respeito do "tempo da política", Goldman sugere a coexistência de concepções de política, uma dos eleitores, para quem ela seria transitória, e outra dos políticos, para quem ela seria "permanente" (2000:318-319).

${ }^{27}$ Certos trabalhos insistem em reduzir a votos de cabresto os dos habitantes do sertão de Pernambuco, sem afirmar esta prática entre os eleitores do litoral. Em um estudo histórico sobre o comportamento eleitoral pernambucano, alguns dos colaboradores parecem aceitar esta idéia (Lavareda e Sá 1986): "No Agreste/Sertão é irrisória a votação do $\mathrm{PCB}$, devido ao padrão de controle coronelístico do eleitorado exercido pelos grandes proprietários da região" (Lavareda 1986:44). "[...] Limoeiro, chefiado por Chico Heráclito, e Serrita, por Chico Romão, são exemplos típicos da vinculação entre a máquina pessedista e estes coronéis, e do 'controle' que estes detinham junto ao seu eleitorado" (Pandolfi 1986:96). Essas afirmativas desconsideram o regime fundiário sertanejo, onde a grande propriedade é exceção. Em segundo lugar, conforme me revelou meu investimento etnográfico, os eleitores não nascem prontos e não são controlados pelos candidatos, a não ser que determinadas condições de controle sejam dadas e mantidas. No entanto, parece que o exercício desse controle é um pressuposto, mais do que nas práticas políticas dos redutos eleitorais, em certa tradição intelectual do pensamento político brasileiro que acaba por dispensar a explicação e descrição de seu funcionamento. Estudos a 
respeito da situação política no Sertão de Pernambuco (Villela 2003; Silva 2000) mostram que não havia monopólio do poder nem mando exclusivista municipal, mesmo durante a Primeira República. Este poder não apenas era disputado entre facções, mas também segmentado no interior de cada uma delas, sem falar ainda no peso de outras instituições estatais (polícia, justiça) plantadas no interior do poder local.

\section{Referências bibliográficas}

AVELINO FILHO, George. 1994. "Clientelismo e política no Brasil. revisitando velhos problemas". Novos Estudos CEBRAP, 38.

BAILEY, F.G. 1968. "Parapolitical systems". In: M. Swartz (ed.), Locallevel politics - social and cultural perspectives. Chicago: Aldine.

. 1971. "Gifts and poison". In: F. G. Bayley (ed.), Gifts and poison. The politics of reputation. Oxford: Basil Blackwell.

BATAILLE, Georges. 1975 [1967]. A parte maldita. Rio de Janeiro: Imago.

BEAUCAGE, Pierre. 1995. "Échange et société: avant et aprés Mauss". Anthropologie et Sociétés, 19:1-2.

BEZERRA, Marcos Otávio. 1999. Em nome das bases: política, favor e dependência pessoal. Rio de Janeiro: Relume Dumará/NuAP.

BOHANNAN, Paul e DALTON, George. 1965. Markets in Africa. London: Anchor Books.

BOURDIEU, Pierre. 1988 [1965]. "O sentimento da honra da sociedade cabília". In: J. G. Peristiani (org.). Honra e vergonha. Valores das so- ciedades mediterrâneas. Lisboa: Caloute Gulbenkian. . 1994 [1980]. Le sens pratique. Paris: Minuit . 1996. "Marginalia. Algumas notas adicionais sobre o dom". Mana, 2(2):7-20.

CARRIER, James G. 1995. "Maussian

Occidentalism: gift and commodity systems". In: J. Carrier (ed.), Occidentalism: images of the West. Oxford: Clarendon Press.

CLASTRES, Pierre (1962) "Échange et pouvoir: philosophie de la chefferie indienne". L'Homme 2.1. 1974. La société contre l'état. Recherches d'anthropologie politique. Paris: Minuit.

DELEUZE, Gilles e GUATTARI, Felix. 1980. Mille-Plateux. Capitalisme et schizophrenie 2. Paris: Minuit.

DUARTE, Nestor. 1966 [1939]. A ordem privada e a organização política nacional. São Paulo: Companhia Editora Nacional.

DURKHEIM, Emile. 1960 [1893]. De la division du travail social. Paris: PUF. EISENSTADT, S. N. e RONIGER, L. 1984. 
Patrons, clients and friends. Interpersonal relations and the structure of trust in society. Cambridge: Cambridge University Press.

GARRIGOU, Alain. 1992. Le vote et la vertu. Comment les Français sont devenus électeurs. Paris: Presses FNSP

GAXIE, Daniel. 1978. Le cens caché. Inégalités culturelles et ségrégation politique. Paris: Seuil.

GOLDMAN, Marcio. 2000. "Uma Teoria Etnográfica da Democracia: a política do ponto de vista do movimento negro de Ilhéus, Bahia, Brasil". Etnográfica, 4 (2).

2001. "Segmentaridade e Movimentos Negros nas Eleições de Ilhéus". Mana, 7 (2):57-94.

.e SILVA, Ana Claudia Cruz da. 1998. "Por que se perde uma Eleição?". In: BARREIRA, Irlys e PALMEIRA, Moacir (orgs.). Candidatos e Candidaturas. Enredos de campanha eleitoral no Brasil. São Paulo: Annablume/UFC.

GODBOUT, Jacques. 1995. "Les 'bonnes raisons' e donner". Anthropologie et Sociétés, 19(1-2).

. e CAILLET, André. 1999 [1992]. O espírito da dádiva. Rio de Janeiro: Editora FGV

GOULDNER, Alvin. 1960. "The norm of reciprocity: a preliminary statement". American Sociological Review, 25 (2):161-178.

GREGORY, Chris. 1982. Gifts and commodities. London: Academic Press.

GRYNSZPAN, Mário. 1990. "Os Idiomas da Patronagem: um estudo da trajetória de Tenório Cavalcanti".
Revista Brasileira de Ciências Sociais, 5(14):73-90.

HEREDIA, Beatriz. 1996. "Política, Família, Comunidade". In: M. Palmeira e M. Goldman (orgs.), Antropologia, voto e representação política. Rio de Janeiro: Contra Capa.

HERZFELD, Michael. 1996. "Embarassment as Pride: narrative resourcefulness and strategies of normativity among cretan animal-thieves". In: Charles L. Briggs, (ed.). Disorderly discourse: narrative, conflict, \& inequality. Oxford: Oxford University Press.

JANKOWSKI, Martin Sánchez. 1991. Islands in the streets. Gangs and American urban society. Berkeley: University of California Press

KARSENTI, Bruno. 1994. Marcel Mauss: le fact social total. Paris: PUF.

KENNY, Michael. 1977. "Patterns of patronage in Spain". In: S. W. Schmidt, L. Guasti, C. H. Landé e J. Scott (eds.). Friends, followers, and factions. A reader in political clientelism. Berkeley: University of California Press.

LANDÉ, Carl. 1977. "The Dyadic Basis of Clientelism". In: S. W. Schmidt, L. Guasti, C. H. Landé e J. Scott (eds.). Friends, followers, and factions. A reader in political clientelism. Berkeley: Univ. of California Press.

LAVAREDA, Antonio. 1986. "A Luta Eleitoral com a Redemocratização: as eleições nacionais de 1945 e o pleito estadual de 1947". In: LAVAREDA, Antonio e SÁ, Constança (orgs.). Poder e Voto. Luta política em Pernambuco. Recife: Massangana. 
LEAL, Vítor Nunes. 1997 [1949]. Coronelismo, enxada e voto. O município e o regime representativo no Brasil. Rio de Janeiro: Nova Fronteira.

LÉVI-STRAUSS, Claude. 1942. "Guerra e Comércio entre os Índios da América do Sul". Revista do Arquivo, 87.

___ 1971 [1966]. Les Structures élementaires de la parenté. Paris: Mouton.

MARQUES, Ana Claudia. 2002. Intrigas e questões. Vingança de família e tramas sociais no sertão de Pernambuco. Rio de Janeiro: Relume Dumará. 1994 [1924]. "Gift-Gift". In: KARADY, Victor (org.). Marcel Mauss OEuvres. Paris: Minuit

1993 [1925]. "Essai sur le Don. Forme et raison de l'échange dans les sociétés archaïques". In: Sociologie et Anthropologie. Paris: PUF.

MALINOWSKI, Bronislaw. 1978 [1922]. Argonautas do Pacífico ocidental. São Paulo: Abril.

MACCORMACK, Geoffrey. 1976. "Reciprocity". Man, 2(1):89-103.

NICHOLAS, Ralph W. 1968. "Rules, Resources and Political Activity". In: M. J. Swartz (org.). Local-level politics. Social and cultural perspectives. Chicago: Aldine.

PALMEIRA, Moacir. 1992. "Voto: racionalidade ou significado?". Revista Brasileira de Ciências Sociais, 7 (20):26-30. . 1996. "Política, facções e voto". In: M. Palmeira e M. Goldman (orgs.). Antropologia, voto e representação política. Rio de Janeiro: Contra Capa.
. 2000. "Eleição municipal, política e cidadania". Tempo e Presença, 310.

PALMEIRA, Moacir e HEREDIA, Beatriz. 1993. "Le Temps de la Politique". Études Rurales, 131-132: 73-87.

PANDOLFI, Dulce Chaves. 1986. "As eleições em Pernambuco de 1950 a 1954". In: A. Lavareda e C. Sá (orgs.). Poder e voto. Luta política em Pernambuco. Recife: Massangana.

PEREIRA DE QUEIROZ, Maria Isaura. 1976. Mandonismo local na vida política brasileira e outros ensaios. São Paulo: Alfa Ômega.

SAHLINS, Marshall. 1976 [1965]. "De la sociologie de l'echange primitif". In: Âge de pierre, âge d'abondance. Paris: Gallimard. 1976 [1968]. "L'esprit du don". In: Âge de pierre, âge d'abondance. Paris: Gallimard.

SCOTT, James. 1977. "Patronage or exploitation?". In: E. Gellner e J. Waterbury (eds.). Patrons and clients in mediterranean societies. London: Ducworth/Center for Mediterranean Studies of the American Universities Field Staff.

SILVERMANN, Sydel. 1977. "Patronage and community-nation relationships in Central Italy". In: S. W. Schmidt, L. Guasti, C. H. Landé e J. Scott (eds.), Friends, followers, and factions. A reader in political clientelism. Berkeley: University of California Press.

SIMONIS, Yvan. 1979 [1968]. LéviStrauss ou a paixão do incesto. Lisboa: Moraes.

STRATHERN, Marilyn. 1988. The gen- 
der of the gift. Problems with women and problems with society in Melanesia. Berkeley: University of California Press.

VEYNE, Paul. 1995 [1976]. Le pain et le cirque. Sociologie historique d'un pluralisme politique. Paris: Seuil. Points Histoire.

VIANNA, Oliveira. 1987 [1949]. Instituições políticas brasileiras. São Paulo: Edusp (2 vols.).

VILLELA, Jorge Mattar. 1999. "A Dívida e a Diferença. Reflexões a Respeito da Reciprocidade". Revista de Antropologia, 54(1):185-220. 2003. O Povo em Armas. Violência e política no Sertão de Pernambuco. Tese de Doutorado, PPGAS/ Museu Nacional/UFRJ.

VILLELA, Jorge Mattar e MARQUES, Ana Claudia. 2002. "Sobre a circulação de recursos nas eleições municipais no Sertão de Pernambuco".
In: B. Heredia, C. Teixeira e I. Barreira (orgs.), Como se fazem eleições no brasil. Rio de Janeiro: Relume Dumará.

WEINER, Annete. 1985. "Inalienable wealth". American Ethonologist, $12(2): 210-228$.

1992. Inalienale possessions. The paradox of keeping while-giving. Berkeley: Univ. of California Press.

WEINGROD, Alex. 1977. "Patronage and power". In: E. Gellner e J. Waterbury (eds.), Patrons and clients in Mediterranean societies. In: London: Ducworth/Center for Mediterranean Studies of the American Universities Field Staff.

WOLF, Eric R. 1966. "Kinship, friendship, and patron-client relation in complex societies". In: M. Banton (ed.). The social anthropology of complex societies. London: Tavistock. 


\section{Resumo}

O artigo pretende mostrar como o dinheiro utilizado nas eleições municipais no Sertão de Pernambuco atua com um desterritorializador das relações sociais previamente existentes, ainda que apenas em alguns casos. Ele é um signo de mercantilização do processo eleitoral que encerra em si mesmo as transações de longo prazo envolvendo o empenho da palavra, das promessas e dos blocos de dívida e crédito, tanto de eleitores quanto de candidatos. Mas o dinheiro em sua forma pura pode ser desmonetarizado pelas próprias relações de dívida e crédito no interior da circulação de recursos-voto por recursos-favor. Por outro lado, bens e serviços que implicam apenas indiretamente o dinheiro podem sofrer um processo de monetarização, dependendo da forma como são aplicados.

Palavras-chave Eleições, Política, Pernambuco, Sertão.

\section{Abstract}

The article aims to show how the money used in the municipal elections in the Pernambuco Outback acts as a deterritorializor of previously existing social relations, albeit in a few cases only. It is a sign of commercializing the electoral process which encompasses the longterm processes involving the pledges, promises and blocks of debt and credit, both those of voters and candidates. But money in its pure form may be demonetarized through the relations of debt and credit themselves within the circulation of voting-resources by favour-resources. On the other hand, goods and services which only indirectly involve money may become monetarized, depending on the form in which they are applied. Key words Elections, Politics, Pernambuco, Sertão (Outback) 